\title{
Outcomes of Stent Retriever versus Aspiration-First Thrombectomy in Ischemic Stroke: A Systematic Review and Meta-Analysis
}

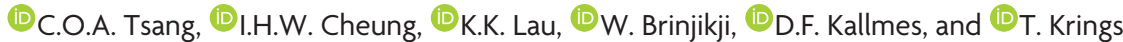

\begin{abstract}
BACKGROUND: There is ongoing debate regarding the optimal first-line thrombectomy technique for large-vessel occlusion.

PURPOSE: We performed a systematic review and meta-analysis of comparative studies on stent retriever-first and aspiration-first thrombectomy.
\end{abstract}

DATA SOURCES: We searched Ovid MEDLINE, PubMed, and EMBASE from 2009 to February 2018.

STUDY SELECTION: Two reviewers independently selected the studies. The primary end point was successful reperfusion (TICI $2 b / 3$ ).

DATA ANALYSIS: Random-effects meta-analysis was used for analysis.

DATA SYNTHESIS: Eighteen studies including 2893 patients were included. There was no significant difference in the rate of final successful reperfusion ( $83.9 \%$ versus $83.3 \%$; OR $=0.87 ; 95 \% \mathrm{Cl}, 0.62 \%-1.27 \%$ ) or good functional outcome (mRS $0-2)$ at 90 days $(\mathrm{OR}=1.07$; $95 \% \mathrm{Cl}, 0.80-1.44)$ between the stent-retriever thrombectomy and aspiration groups. The stent-retriever thrombectomy-first group achieved a statistically significant higher $\mathrm{TICI} 2 \mathrm{~b} / 3$ rate after the first-line device than the aspiration-first group $(74.9 \%$ versus $66.4 \%$; OR $=$ 1.53; $95 \% \mathrm{Cl}, 1.14 \%-2.05 \%)$ and resulted in lower use of a rescue device (19.9\% versus $32.5 \%$; OR $=0.36 ; 95 \% \mathrm{Cl}, 0.14 \%-0.90 \%)$. The aspiration-first approach resulted in a statistically shorter groin-to-reperfusion time (weighted mean difference, 7.15 minutes; $95 \% \mathrm{Cl}$, 1.63-12.67 minutes). There was no difference in the number of passes, symptomatic intracerebral hemorrhage, vessel dissection or perforation, and mortality between groups.

LIMITATIONS: Most of the included studies were nonrandomized. There was significant heterogeneity in some of the outcome variables. CONCLUSIONS: Stent-retriever thrombectomy-first and aspiration-first thrombectomy were associated with comparable final reperfusion rates and functional outcome. Stent-retriever thrombectomy was superior in achieving reperfusion as a stand-alone first-line technique, with lower use of rescue devices but a longer groin-to-reperfusion time.

ABBREVIATIONS: ADAPT $=$ A Direct Aspiration, First Pass Technique for the Endovascular Treatment of Stroke; PRISMA $=$ Preferred Reporting Items for Systematic Reviews and Meta-Analyses; RCT = randomized controlled trial; SRT = stent-retriever thrombectomy

E ndovascular thrombectomy is recommended as a standard of care for anterior circulation acute ischemic stroke secondary to large-vessel occlusion. ${ }^{1}$ This treatment was established in 2015

Received April 19, 2018; accepted after revision August 16.

From the Division of Neurosurgery (C.O.A.T.), Department of Surgery, and Division of Neurology (K.K.L.), Department of Medicine, University of Hong Kong, Hong Kong; Department of Medical Imaging (C.O.A.T., W.B., T.K.), Toronto Western Hospital, Toronto, Ontario, Canada; Department of Diagnostic Radiology (I.H.W.C.), Queen Mary Hospital, Hong Kong; and Department of Radiology (W.B., D.F.K.), Mayo Clinic, Rochester, Minnesota.

This study was supported by the Health and Medical Research Fund of Hong Kong (01150027).

Please address correspondence to Chun On Anderson Tsang, Room 701, Administrative Block, Department of Neurosurgery, Queen Mary Hospital, 102

Pokfulam Rd, Hong Kong; e-mail: acotsang@hku.hk when multiple randomized controlled trials (RCTs) established the clinical efficacy and safety of modern stent-retriever thrombectomy (SRT) in removing the obstructing thrombus in acute ischemia. $^{2-6}$ A Direct Aspiration, First Pass Technique for the Endovascular Treatment of Stroke (ADAPT) is an alternative thrombectomy technique that has become the standard of care at many centers. ${ }^{7}$ This is performed by advancing a large-bore catheter (typically with an inner diameter of $\geq 0.060$ inch) to the face of the thrombus, followed by its removal by aspiration alone or withdrawal of the catheter while aspirating. Previous observational studies focusing on ADAPT reported a higher rate of com-

\footnotetext{
- Indicates open access to non-subscribers at www.ajnr.org

http://dx.doi.org/10.3174/ajnr.A5825
} 
plete revascularization and potentially a shorter time from groin puncture to reperfusion compared with stent-retriever thrombectomy. ${ }^{8}$ However, recent randomized trials comparing SRT with ADAPT have failed to demonstrate the superiority of ADAPT in technical or clinical outcomes. ${ }^{9}$ To address the ongoing debate of the optimal first-line thrombectomy technique, we performed a meta-analysis of comparative studies reporting outcomes on SRT versus ADAPT as a first-line approach.

\section{MATERIALS AND METHODS}

\section{Search Strategy and Selection Criteria}

A systematic literature review was performed following the Preferred Reporting Items for Systematic Reviews and Meta-Analyses (PRISMA) guidelines. ${ }^{10}$ The English literature was searched with Ovid MEDLINE, PubMed, and EMBASE from January 2009 to February 2018. The following terms and their combinations were used as keywords or Medical Subject Headings terms: "mechanical thrombectomy," "endovascular," "stroke," "ADAPT," "aspiration," "stent retriever," and "first-pass." We also searched the references of relevant articles and contacted experts in the field to identify additional studies pertaining to the outcome of different thrombectomy techniques that were not included in the initial literature search.

Studies identified were then evaluated to meet the following inclusion criteria: 1) studies comparing the outcomes of the SRTfirst and aspiration-first strategies; 2) studies reporting separately the clinical and technical outcomes of the SRT and aspiration groups; and 3) studies with at least 10 patients each in the SRT or aspiration group. The exclusion criteria were the following: 1) noncomparative studies reporting outcomes only on 1 group (SRT or aspiration); 2) studies that predominantly used the first generation of aspiration catheters (eg, Penumbra Separator 0.041 [Penumbra, Alameda, California] or smaller catheters, with or without the Separator) in the aspiration arm; and 3) studies that did not separate outcomes by the first-line thrombectomy technique adopted. Both randomized and observational studies were included.

\section{Data Items and Extraction}

Patients were divided into 2 groups: SRT-first and aspirationfirst. For this study, patients were considered to have SRT-first if any stent retriever was used in the first thrombectomy attempt, with or without balloon-guiding catheters or simultaneous distal aspiration (ie, Solumbra technique). Those receiving only direct aspiration with large-bore distal-access catheters in the first thrombectomy attempt were considered aspiration-first.

The primary end point was the rate of successful reperfusion defined as the final Thrombolysis in Cerebral Infarction score of $2 b / 3$. Other clinical outcomes included the following: good functional outcome defined as a modified Rankin Scale $0-2$ at 90 days, 90-day mortality, symptomatic intracererbal hemorrhage, and complications of vessel dissection or perforation. Other technical outcomes studied included the following: the rate of complete reperfusion (TICI 3 ), the rate of TICI $2 \mathrm{~b} / 3$ achieved with only the first device, the use of a rescue device, the number of thrombectomy passes, and the time from groin puncture to reperfusion.

\section{Risk of Bias Assessment}

The included studies were assessed for risk of bias by 2 independent readers (A.C.O.T. and I.H.W.C.) with the Newcastle Ottawa Scale. ${ }^{11}$ This is an 8 -item tool for nonrandomized studies included in systematic reviews and meta-analyses, in which the selection, comparability, and ascertainment of outcomes of the study groups are assessed. The scale ranges from 0 to 9 , with the higher score indicating lower risk of bias. Studies that used welldefined selection criteria, with comparable baseline stroke severity; patient demographics; onset-to-groin puncture time, with contemporaneous use of SRT; and aspiration thrombectomy and those that had an independent assessment of clinical and technical outcomes are considered to have a low risk of bias.

\section{Statistical Analysis}

We extracted from each study a $2 \times 2$ table for binary outcomes and the mean group sample size and a variability measure for continuous outcomes. The pooled outcomes were meta-analyzed using a random-effects model. ${ }^{12}$ Heterogeneity of the studies not attributable to chance was quantified with the $\mathrm{I}^{2}$ statistic. ${ }^{13}$ The $95 \%$ confidence intervals of the odds ratios for binary outcomes and the weighted mean differences for continuous outcomes were reported. Some included studies reported continuous outcomes with median and interquartile range; these were converted to a mean and SD value based on the assumption of a log-normal distribution of the original measure. When the SD or the interquartile range for a specific outcome was not reported in the article, it was extrapolated from other studies when such data were available. If $>10$ studies were identified, a funnel plot was constructed to explore the impact of publication bias.

Only 3 of the 18 included studies were randomized by the first thrombectomy strategy. To address the potential heterogeneity between the 2 study groups, we conducted meta-regression to test the influence of moderators, including baseline stroke severity measured by the National Institutes of Health Stroke Scale and age. Sensitivity analyses were performed by studying the comparative outcomes, including only those studies that were RCTs, those that included predominantly $(>90 \%)$ anterior circulation thrombectomy, and those that used balloon-guiding catheters with SRT consistently. Meta-analysis and meta-regression were performed with OpenMeta[Analyst] (http://www.cebm.brown. edu/openmeta/). ${ }^{14}$

\section{RESULTS}

\section{Literature Search}

The initial literature search yielded 862 articles. The titles and abstracts of these were read, and 818 articles were excluded for irrelevance. Of the remaining 44 articles, 14 were excluded because they were conference abstracts, and 7 were excluded because they were review articles or editorials. After review, 2 articles were excluded for overlapping patient populations, and 4 studies were excluded for predominantly using a previous generation of thrombectomy devices. One additional study was identified by contacting experts in the field, yielding a total of 18 studies eligible for analysis. ${ }^{915-31}$ The PRISMA flow diagram is provided in Fig 1.

AJNR Am J Neuroradiol 39:2070-76 Nov 2018 www.ajnr.org 


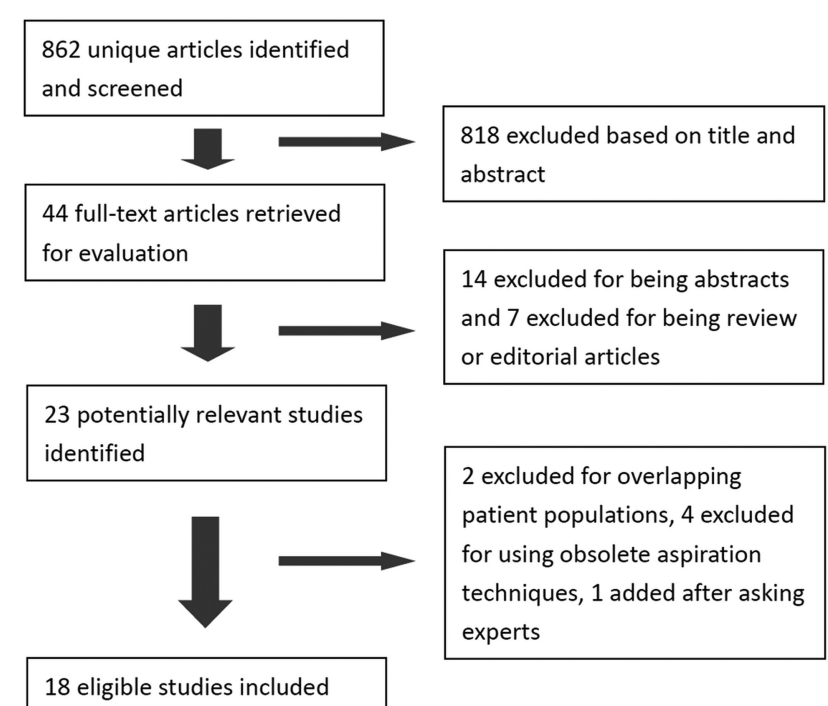

FIG 1. Literature search flowchart.

\section{Study and Patient Characteristics}

A total of 2893 patients (1564 with SRT and 1329 with aspirationfirst) in the 3 randomized multicenter trials and 15 retrospective studies were included. The mean age of patients in the SRT and aspiration group were 69.8 and 68.7 years, respectively. For the SRT group, the mean baseline NIHSS score was 15.8, and that in the aspiration group was 15.3. The median ASPECTS in both groups was 8 .

Balloon-guiding catheters were routinely used in 5 studies, intermittently used in 2 studies, and not used in 11 studies. In 6 studies, simultaneous adjuvant distal aspiration with SRT was used in the first pass in a variable proportion of patients. All except 3 studies reported predominantly anterior circulation thrombectomy ( $>85 \%$ ), including the 3 randomized trials. There were 4 retrospective single-center studies reporting only posterior circulation thrombectomy, comprising 138 patients $(8.8 \%)$ in the SRT arm and 126 patients $(9.5 \%)$ in the aspiration arm. Four studies had a low risk of bias, 12 had a moderate risk of bias, and 2 had a high risk of bias. The included studies are summarized in Table 1.

\section{Technical Outcomes}

When we compared SRT-first and aspiration-first thrombectomy, there was no statistically significant difference in the rate of final successful reperfusion (TICI 2b/3) (83.9\% versus $83.3 \%$; $\mathrm{OR}=0.87 ; 95 \% \mathrm{CI}, 0.62 \%-1.27 \%)$ or complete reperfusion (TICI 3) $(38.1 \%$ versus $40.3 \%$; OR $=0.82$; 95\% CI, $0.49 \%-$ $1.37 \%)$. The SRT-first group achieved a statistically significant higher TICI $2 \mathrm{~b} / 3$ rate after the first-line strategy than the aspiration-first group $(74.9 \%$ versus $66.4 \%$; OR $=1.53$; $95 \% \mathrm{CI}$, $1.14 \%-2.05 \%)$ and this resulted in lower use of the rescue device (19.9\% versus $32.5 \%$; OR $=0.36$; 95\% CI, $0.14 \%-0.90 \%$ ) (Fig 2). The aspiration-first approach resulted in a statistically shorter groin-to-reperfusion time (weighted mean difference, 7.15 minutes; 95\% CI, 1.63-12.67). There was no difference in the number of passes required to achieve reperfusion between groups.

\section{Clinical Outcomes}

There was no statistical difference in the rate of good functional outcome ( $\mathrm{mRS} 0-2$ ) at 90 days between groups ( $\mathrm{OR}=1.07 ; 95 \%$ CI, $0.80-1.44)$. There was also no significant difference in the mortality rate, the rate of symptomatic intracerebral hemorrhage, emboli to new territories, vessel dissection, or perforation between the 2 groups. These results are summarized in Tables 2 and 3.

\section{Publication Bias and Study Heterogeneity}

Funnel plot analysis did not suggest publication bias (Fig 3). There was low heterogeneity $\left(\mathrm{I}^{2}<50 \%\right)$ for the following outcomes: the TICI $2 \mathrm{~b} / 3$ rate after the first-line approach $\left(\mathrm{I}^{2}=31 \%\right)$, mortality rate $\left(\mathrm{I}^{2}=28 \%\right)$, risk of symptomatic intracerebral hemorrhage $\left(\mathrm{I}^{2}=0 \%\right)$, emboli to new territories $\left(\mathrm{I}^{2}=0 \%\right)$, and vessel dissection or perforation $\left(\mathrm{I}^{2}=26 \%\right)$. There was moderate substantial heterogeneity $\left(\mathrm{I}^{2}>50 \%\right)$ for the following outcomes: final rate of TICI $2 \mathrm{~b} / 3\left(\mathrm{I}^{2}=54 \%\right)$, final rate of TICI $3\left(\mathrm{I}^{2}=79.5 \%\right)$, mRS $0-2$ at 90 days $\left(I^{2}=62 \%\right)$, the need for a rescue device $\left(\mathrm{I}^{2}=\right.$ $93 \%)$, groin-to-reperfusion time $\left(\mathrm{I}^{2}=79 \%\right)$, and the number of passes required $\left(\mathrm{I}^{2}=77 \%\right)$

Meta-regression analyses performed on outcomes with high heterogeneity (final TICI $2 \mathrm{~b} / 3$ and mRS $0-2$ at 90 days) did not identify variables explaining differences between studies.

\section{Sensitivity Analysis}

We performed a subgroup analysis to determine whether the outcomes were different in anterior circulation stroke versus posterior circulation stroke. In the 9 studies that included predominantly $(>90 \%)$ anterior circulation stroke, there was no statistically significant difference in the final TICI $2 b / 3$ rate between groups $(\mathrm{OR}=0.892 ; 95 \% \mathrm{CI}, 0.59-1.35)$. Four studies reporting posterior circulation stroke only were included. The use of the SRT-first approach in posterior circulation stroke was associated with a statistically significant lower successful reperfusion (OR = 0.47; 95\% CI, 0.25-0.91).

When we included only the 3 randomized controlled trials, we found no difference in the final TICI $2 \mathrm{~b} / 3$ rate $(\mathrm{OR}=1.05 ; 95 \%$ CI, $0.58-1.90)$ and good functional outcome (OR $=1.04 ; 95 \%$ CI, 0.79-1.37). There was a non-statistically significant higher chance in the SRT-first group of achieving TICI $2 \mathrm{~b} / 3$ after the first-line approach $(\mathrm{OR}=1.26$; 95\% CI, 0.85-1.86).

When including only the 5 studies that consistently used balloon-guiding catheters with SRT, we again found no difference in the final TICI $2 \mathrm{~b} / 3$ rate $(\mathrm{OR}=0.95 ; 95 \% \mathrm{CI}, 0.54-1.67)$ and good functional outcome $(\mathrm{OR}=1.22 ; 95 \% \mathrm{CI}, 0.91-1.64)$. There was a non-statistically significant higher chance in the SRT-first group of achieving TICI $2 \mathrm{~b} / 3$ after the first-line approach $(\mathrm{OR}=1.26$; 95\% CI, 0.92-1.73).

When we excluded the study that used the Penumbra 3D Separator device, ${ }^{28}$ which was different in design from other conventional stent retrievers, there were no differences in the final TICI $2 \mathrm{~b} / 3$ rate $(\mathrm{OR}=0.88 ; 95 \% \mathrm{CI}, 0.62-1.25)$. When we included only the 3 studies that reported TICI $2 \mathrm{c} / 3$ outcomes, there were no differences in the final TICI $2 \mathrm{c} / 3$ rate $(\mathrm{OR}=1.10$; 95\% CI, $0.61-$ 1.89 ) between groups. 
Table 1: Studies included in the meta-analysis

\begin{tabular}{|c|c|c|c|c|c|c|c|c|}
\hline Author & Year & $\begin{array}{l}\text { No. of } \\
\text { Patients, } \\
\text { SRT/Asp }\end{array}$ & $\begin{array}{c}\text { Mean Age } \\
\text { (yr), SRT/Asp }\end{array}$ & $\begin{array}{l}\text { Mean Baseline } \\
\text { NIHSS, SRT/Asp }\end{array}$ & $\begin{array}{c}\text { Mean Baseline } \\
\text { ASPECTS, SRT/Asp }\end{array}$ & $\begin{array}{c}\text { Anterior } \\
\text { Circulation } \\
(\%)\end{array}$ & $\begin{array}{l}\text { Study } \\
\text { Design }\end{array}$ & $\begin{array}{c}\text { Risk of } \\
\text { Bias (NOS) }\end{array}$ \\
\hline Delgado Almandoz et a $\left.\right|^{17}$ & 2016 & $55 / 45$ & $69.6 / 66.1$ & $16.8 / 19.2$ & $8.2 / 9.1$ & $94 \%$ & Retrospective, single-center, case-control & 7 \\
\hline Turk et $\mathrm{al}^{18}$ & 2015 & $30 / 64$ & $62.5 / 68.5$ & $17 / 16.5$ & NA & $90 \%$ & Retrospective, single-center, case-control & 7 \\
\hline Son et $\mathrm{al}^{29}$ & 2016 & $13 / 18$ & $68.9 / 66.4$ & $27.3 / 21.3$ & NA & $0 \%$ & Retrospective, single-center, case-control & 6 \\
\hline Kim et $\mathrm{al}^{20}$ & 2017 & $16 / 25$ & $76.5 / 71$ & $10.5 / 15$ & $7 / 8$ & $100 \%$ & Retrospective, single-center, case-control & 7 \\
\hline Lapergue et al $(\mathrm{a})^{19}$ & 2016 & $119 / 124$ & $65.5 / 64.3$ & $15.9 / 15.9$ & $8 / 9$ & $100 \%$ & Retrospective, multicenter, case-control & 7 \\
\hline Mokin et al $(a)^{16}$ & 2016 & $58 / 42$ & NA & NA & NA & $0 \%$ & Retrospective, multicenter, case-control & 7 \\
\hline Gerber et $\mathrm{al}^{22}$ & 2017 & $13 / 20$ & $63.2 / 62.8$ & $25 / 18$ & $6.5 / 7.5$ & $0 \%$ & Retrospective, single-center, case-control & 6 \\
\hline Hentschel et $a^{15}$ & 2017 & $67 / 69$ & $66.2 / 66.1$ & NA & NA & $90 \%$ & Retrospective, single-center, case-control & 7 \\
\hline Hesse et $\mathrm{al}^{23}$ & 2018 & $286 / 164$ & $74 / 72$ & $15.5 / 15.3$ & $8 / 8$ & $100 \%$ & Retrospective, multicenter, case-control & 5 \\
\hline Jadhav et $\mathrm{al}^{24}$ & 2017 & 195/112 & $69 / 66$ & $17 / 17$ & $9 / 9$ & $87 \%$ & Retrospective, single-center, case-control & 6 \\
\hline Lapergue et al (b) ${ }^{9}$ & 2017 & $189 / 192$ & $68.1 / 71.7$ & $16.1 / 16.3$ & $7 / 7$ & $100 \%$ & Randomized controlled trial, multicenter & 9 \\
\hline Maegerlein et $\mathrm{al}^{25}$ & 2017 & $61 / 36$ & $75.8 / 72.4$ & NA & NA & $89 \%$ & Retrospective, multicenter, case-control & 5 \\
\hline Mokin et al (b) ${ }^{21}$ & 2017 & $62 / 51$ & NA & NA & NA & $100 \%$ & Retrospective, multicenter, case-control & 8 \\
\hline Stapleton et $\mathrm{al}^{31}$ & 2018 & $70 / 47$ & $69.4 / 63.5$ & $16.5 / 16.5$ & $8.3 / 8$ & $100 \%$ & Retrospective, single-center, case-control & 7 \\
\hline Gory et $\mathrm{al}^{26}$ & 2018 & $54 / 46$ & $67 / 61$ & $20 / 14$ & $8 / 7$ & $0 \%$ & Retrospective, multicenter, case-control & 7 \\
\hline Mocco et $\mathrm{al}^{27}$ & 2018 & $136 / 133$ & $71.1 / 71.8$ & $7 / 6$ & NA & $100 \%$ & Randomized controlled trial, multicenter & 9 \\
\hline Nogueira et $\mathrm{al}^{28}$ & 2018 & $95 / 97$ & $67.3 / 66.5$ & $18 / 18$ & $8 / 8$ & $98 \%$ & Randomized controlled trial, multicenter & 9 \\
\hline Nishi et $\mathrm{al}^{30}$ & 2018 & $45 / 44$ & $73.1 / 77.8$ & $19 / 17$ & NA & $88 \%$ & Retrospective, single-center, case-control & 7 \\
\hline
\end{tabular}

Note:-NOS indicates Newcastle-Ottawa Scale; NA, not available; Asp, aspiration.

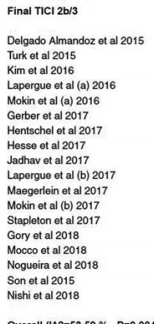

A

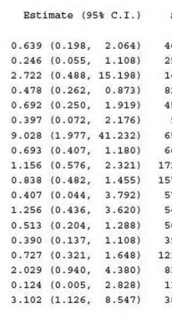

$11 / 13$
$30 / 45$

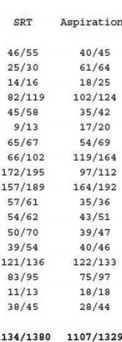

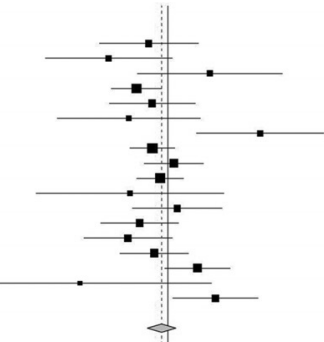

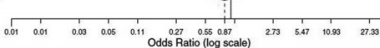

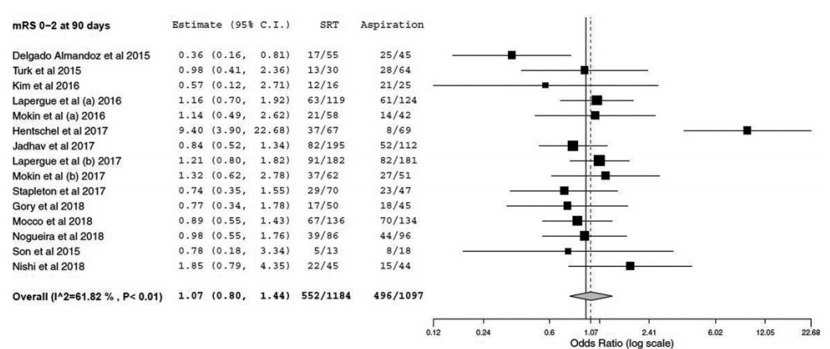

B

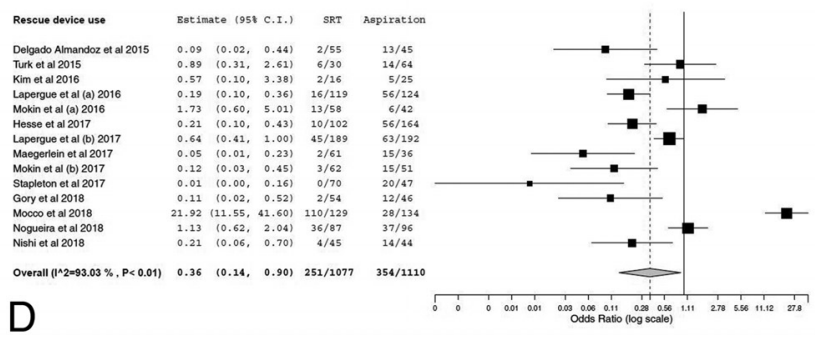

FIG 2. Forest plot of meta-analysis results. $A$, Final successful reperfusion was $\mathrm{TICl} 2 \mathrm{~b} / 3$. B, Good functional outcome mRS $0-2$ at 90 days. Successful reperfusion $\mathrm{TICl} 2 \mathrm{~b} / 3$ after the first-line approach $(C)$ and the use of a rescue device $(D)$.

Table 2: Summary of meta-analysis outcomes

\begin{tabular}{lccc}
\multicolumn{1}{c}{ Outcome } & Odds Ratio & $\mathbf{9 5 \%} \mathbf{C l}$ & $\mathbf{I}^{\mathbf{2}}$ \\
\hline Final $\mathrm{TICl} 2 \mathrm{~b} / 3$ & 0.87 & $0.62-1.27$ & $53.6 \%$ \\
Final $\mathrm{TICl} 3$ & 0.82 & $0.49-1.37$ & $79.5 \%$ \\
First-line approach, $\mathrm{TICl}$ 2b/3 & 1.53 & $1.14-2.05$ & $31.1 \%$ \\
mRS 0-2 at 90 days & 1.07 & $0.80-1.44$ & $61.8 \%$ \\
Mortality & 0.91 & $0.69-1.20$ & $28.1 \%$ \\
Rescue device & 0.36 & $0.14-0.90$ & $93.0 \%$ \\
Dissection or perforation & 1.26 & $0.52-3.08$ & $26.3 \%$ \\
ENT & 1.11 & $0.70-1.74$ & $0 \%$ \\
sICH & 1.20 & $0.78-1.84$ & $0 \%$ \\
\hline
\end{tabular}

Note:-ENT indicates emboli to new territories; $\mathrm{sICH}$, symptomatic intracranial hemorrhage.

\section{DISCUSSION}

Our meta-analysis of 2893 patients from 18 studies found no significant difference in terms of the final revascularization rate and functional outcome between aspiration-first and SRT-first thrombectomy for large-vessel occlusion stroke. Notably, stent retriever use was superior in achieving successful reperfusion as a stand-alone technique, compared with aspiration. The need for a
Table 3: Summary of meta-analysis outcomes

\begin{tabular}{lcrc}
\hline & $\begin{array}{c}\text { Weighted Mean } \\
\text { Difference }\end{array}$ & \multicolumn{1}{c}{$\mathbf{9 5 \%} \mathbf{C l}$} & $\mathbf{I}^{\mathbf{2}}$ \\
\hline Groin to perfusion (min) & 7.15 & $1.63-12.67$ & $79.0 \%$ \\
No. of passes & 0.06 & $-0.40-0.52$ & $77.0 \%$ \\
\hline
\end{tabular}

rescue device was also significantly less when SRT was adopted as a first approach instead of aspiration. The comparable final reperfusion rate in the aspiration group was achieved with the use of a rescue device after the initial failed attempts with contact aspiration, which was necessary in $32.5 \%$ of patients. These findings are important because they suggest that despite SRT and aspiration-first strategies being able to achieve similar final revascularization rates and functional outcomes, SRT appears to be more effective than aspiration as a primary treatment technique for achieving TICI $2 \mathrm{~b} / 3$ revascularization.

Endovascular thrombectomy with stent retrievers for largevessel occlusion stroke has been established as the standard of care since 2015. ${ }^{32}$ The use of direct-contact aspiration thrombectomy 
Funnel plot with pseudo 95\% confidence limits

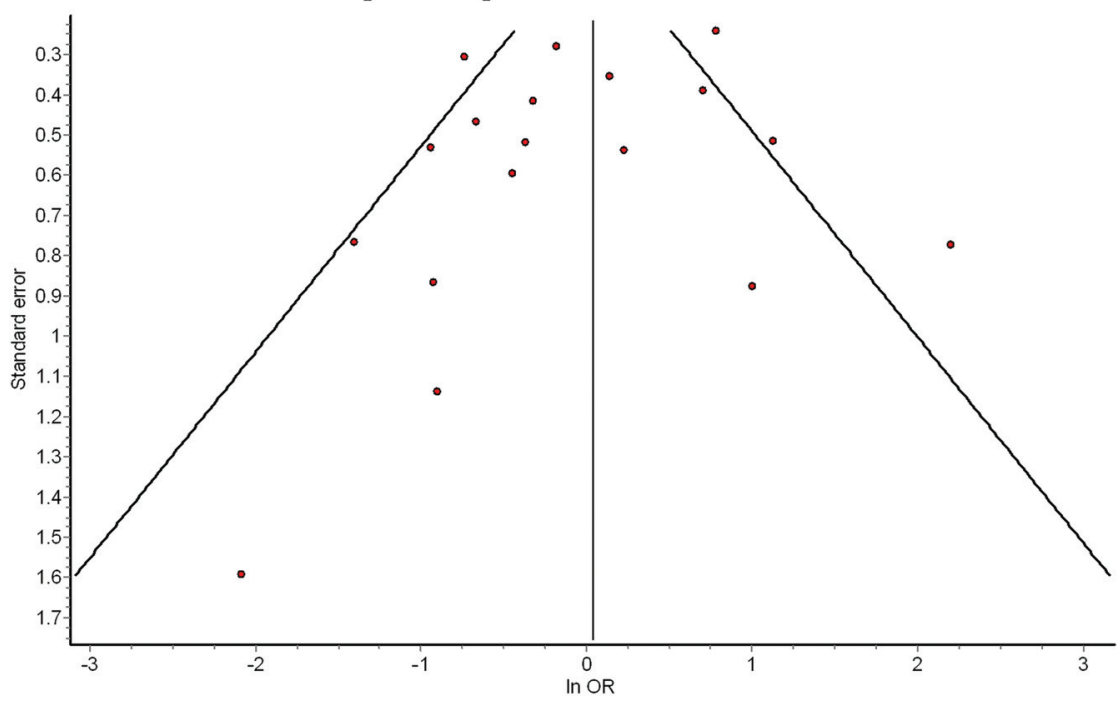

FIG 3. Funnel plot for publication bias.

is another common technique but was not supported by class I evidence. Nevertheless, aspiration thrombectomy as a first-line approach is widely practiced in the United States, Hong Kong, and Italy despite the availability of the proved and efficacious stent-retriever thrombectomy. ${ }^{33-35}$ The THERAPY (The Randomized, Concurrent Controlled Trial to Assess the Penumbra System's Safety and Effectiveness in the Treatment of Acute Stroke; NCT01429350) trial, which compared aspiration thrombectomy with best medical therapy, was halted early and did not demonstrate efficacy. ${ }^{36}$ While recent meta-analyses of uncontrolled observational studies focusing solely on the aspiration technique reported higher complete reperfusion rates and shorter procedure times than SRT, ${ }^{8,37}$ these conclusions were confounded by the different patient-selection criteria and baseline stroke severity in the included single-arm studies. The published RCTs on this subject demonstrated noninferiority of aspiration thrombectomy compared with SRT in the final reperfusion rate but were underpowered to compare other clinical outcomes such as functional status and complication rates. ${ }^{8,37}$ To address these limitations, the present review included only studies that compared both SRT-first and aspirationfirst approaches in the same patient cohort, as well as the 3 recently published/presented RCTs investigating these 2 groups.

One of the notable findings from our study is that SRT could achieve higher rates of TICI $2 \mathrm{~b} / 3$ reperfusion without the help of rescue therapy than aspiration thrombectomy alone. This is important because the literature has focused more on the first-pass effect during thrombectomy for acute ischemic stroke, defined as achieving complete recanalization with a single pass. In a recently published post hoc analysis of the North American Solitaire Acute Stroke Registry, Zaidat et $\mathrm{al}^{38}$ found that patients who achieved TICI $2 b / 3$ on a first pass had significantly better clinical outcomes than those who did not. Independent predictors of a first-pass effect included the use of a balloon-guiding catheter and noninternal carotid artery terminus occlusion. While we were not able to examine first-pass recanalization rates between SRT and aspiration in this meta-analysis, SRT alone achieved higher recanalization rates than aspiration alone. Ultimately, the fact that SRT was used as a rescue therapy in nearly one-third of aspiration cases while aspiration was needed as rescue therapy in nearly one-fifth of SRT cases suggests that SRT has some technical advantages in clot retrieval.

There are a number of advantages to aspiration thrombectomy compared with SRT. With contact aspiration thrombectomy, it is not necessary to traverse the occluding thrombus, thus theoretically reducing the risk of vessel perforation and downstream emboli. While cases of catastrophic vessel perforation with the use of SRT have been reported, the incidence was low. ${ }^{39}$ Our review did not show any significant difference in the safety profiles between the 2 groups. Rates of vessel perforation, dissection, and symptomatic ICH were comparable. Another proposed advantage of aspiration over SRT is the shorter procedural time. The aspiration-first approach was associated with a 7-minute advantage in groin-to-reperfusion time in the meta-analysis. In the 3 randomized studies comparing the 2 approaches, the aspiration-first approach also resulted in a shorter procedural time of 10-13 minutes. $^{9,27,28}$ Nevertheless, this advantage in rapidity did not translate to improved patient outcome in any of those trials.

While the overall final reperfusion rate is comparable, there remain uncertainties about whether SRT or aspiration is superior in selected vessel locations or the etiology of stroke. Subgroup analysis of the 4 posterior circulation stroke studies including 264 patients showed that SRT was inferior to aspiration in terms of reperfusion rates. However, the sample size was too small to draw any definitive conclusions. None of the included studies reported the comparative efficacy of aspiration and SRT stratified by the specific occluded vessel to allow subgroup analysis. The etiology of large-vessel occlusion may also affect the efficacy of thrombectomy. In large-vessel occlusion secondary to intracranial artery stenosis, early experience with stent retrievers in this group of patients resulted in a lower reperfusion rate and poorer outcome. In addition, rescue therapy with balloon angioplasty or intra-arterial thrombolytic infusion was frequently required..$^{40}$ The shearing force exerted over the atherosclerotic plaque during stent retrieval may be the culprit, and the optimal first-line thrombectomy strategy in this group of patients needs further investigation. Techniques combining SRT and aspiration have been increasingly used, but their superiority over SRT or aspiration alone remains to be defined in randomized studies. ${ }^{17,41,42}$ Future studies on the optimal thrombectomy technique should also adopt more robust outcome variables, including TICI $2 \mathrm{c} / 3$ angiographic outcome and the first-pass success rate, ${ }^{38,43}$ and should consider other aspects such as delayed effects on the vessel wall and the relative cost-effectiveness of different techniques.

\section{Limitations}

Our study has limitations. Apart from the 3 RCTs, most of the included studies were nonrandomized, thus introducing selection 
bias. When performing subgroup analysis on only the 3 recent RCTs, we found results similar to those in our meta-analysis. We limited the review to comparative studies with control groups to compare the relative efficacy of SRT and aspiration and excluded those studies that used predominantly previous generations of thrombectomy catheters or devices. There was significant statistical heterogeneity in some of the outcome variables that can impact the validity of our results. Another limitation is that in some cases SRT was performed with simultaneous aspiration (ie, Solumbra technique) and we could not perform subgroup analyses of Solumbra versus SRT-alone versus aspiration. While TICI $2 \mathrm{c} / 3$ is increasingly recognized as a better angiographic outcome measure and correlates better with clinical outcome, only 3 of the included studies reported TICI $2 \mathrm{c} / 3$ rates and the subgroup analysis on these studies showed similar results.

\section{CONCLUSIONS}

This systematic review and meta-analysis of 18 studies and 2893 patients found that SRT-first and aspiration-first thrombectomy were associated with comparable final reperfusion rates and functional outcomes. SRT was superior in achieving reperfusion as a stand-alone first-line technique, with lower use of rescue devices but a longer groin-to-reperfusion time. There were no significant differences in complication rates and mortality. The optimal firstline thrombectomy approach for specific location or stroke etiology remains unclear.

Disclosures: Chun On Anderson Tsang—RELATED: Grant: Health and Medical Research Fund of Hong Kong (01150027), Comments: a peer-reviewed medical research grant provided by the Hong Kong government through the Food and Health Bureau.* David F. Kallmes - UNRELATED: Consultancy: Medtronic, Comments: clinical trials*; Grants/Grants Pending: Medtronic, Neuravi, Comments: preclinical and clinical research*; Patents (Planned, Pending or Issued): Mayo Clinic, Comments: balloon-guided devices; Stock/Stock Options: Marblehead Medical, Comments: stroke access device development. *Money paid to the institution.

\section{REFERENCES}

1. Powers WJ, Rabinstein AA, Ackerson T, et al; American Heart Association Stroke Council. 2018 Guidelines for the Early Management of Patients with Acute Ischemic Stroke: A Guideline for Healthcare Professionals from the American Heart Association/American Stroke Association. Stroke 2018;49:e46-110 CrossRef Medline

2. Berkhemer OA, Fransen PS, Beumer D, et al; MR CLEAN Investigators. A randomized trial of intraarterial treatment for acute ischemic stroke. N Engl J Med 2015;372:11-20 CrossRef Medline

3. Campbell BC, Mitchell PJ, Kleinig TJ, et al; EXTEND-IA Investigators. Endovascular therapy for ischemic stroke with perfusion-imaging selection. $N$ Engl J Med 2015;372:1009-18 CrossRef Medline

4. Goyal M, Demchuk AM, Menon BK, et al; ESCAPE Trial Investigators. Randomized assessment of rapid endovascular treatment of ischemic stroke. $N$ Engl J Med 2015;372:1019-30 CrossRef Medline

5. Jovin TG, Chamorro A, Cobo E, et al; REVASCAT Trial Investigators. Thrombectomy within $\mathbf{8}$ hours after symptom onset in ischemic stroke. N Engl J Med 2015;372:2296-306 CrossRef Medline

6. Saver JL, Goyal M, Bonafe A, et al; SWIFT PRIME Investigators. Stent-retriever thrombectomy after intravenous t-PA vs. t-PA alone in stroke. $N$ Engl J Med 2015;372:2285-95 CrossRef Medline

7. Turk AS, Frei D, Fiorella D, et al. ADAPT FAST study: a direct aspiration first pass technique for acute stroke thrombectomy. $\mathrm{J} \mathrm{Neu}$ rointerv Surg 2014;6:260-64 CrossRef Medline

8. Phan K, Dmytriw AA, Teng I, et al. A direct aspiration first pass technique vs standard endovascular therapy for acute stroke: a sys- tematic review and meta-analysis. Neurosurgery 2018;83:19-28 CrossRef Medline

9. Lapergue B, Blanc R, Gory B, et al; ASTER Trial Investigators. Effect of endovascular contact aspiration vs stent retriever on revascularization in patients with acute ischemic stroke and large vessel occlusion: the ASTER randomized clinical trial. JAMA 2017; 318: 443-52 CrossRef Medline

10. Moher D, Liberati A, Tetzlaff J, et al; PRISMA Group. Preferred reporting items for systematic reviews and meta-analyses: the PRISMA statement. J Clin Epidemiol 2009;62:1006-12 CrossRef Medline

11. Wells GA, Shea B, O'Connell D, et al. The Newcastle-Ottawa Scale (NOS) for assessing the quality of nonrandomised studies in metaanalyses. 2013. http://www.ohri.ca/programs/clinical_epidemiology/ oxford.asp. Accessed February 6, 2018

12. DerSimonian R, Laird N. Meta-analysis in clinical trials revisited. Contemp Clin Trials 2015;45(Pt A):139-45 CrossRef Medline

13. Higgins JP, Thompson SG, Deeks JJ, et al. Measuring inconsistency in meta-analyses. BMJ 2003;327:557-60 CrossRef Medline

14. Wallace BC, Dahabreh IJ, Trikalinos TA, et al. Closing the gap between methodologists and end-users: $\mathrm{R}$ as a computational backend. J Stat Softw 2012;19;1-15

15. Hentschel KA, Daou B, Chalouhi N, et al. Comparison of non-stent retriever and stent retriever mechanical thrombectomy devices for the endovascular treatment of acute ischemic stroke. J Neurosurg 2017;126:1123-30 CrossRef Medline

16. Mokin M, Sonig A, Sivakanthan S, et al. Clinical and procedural predictors of outcomes from the endovascular treatment of posterior circulation strokes. Stroke 2016;47:782-88 CrossRef Medline

17. Delgado Almandoz JE, Kayan Y, Young ML, et al. Comparison of clinical outcomes in patients with acute ischemic strokes treated with mechanical thrombectomy using either Solumbra or ADAPT techniques. J Neurointerv Surg 2016;8:1123-28 CrossRef Medline

18. Turk AS, Turner R, Spiotta A, et al. Comparison of endovascular treatment approaches for acute ischemic stroke: cost effectiveness, technical success, and clinical outcomes. J Neurointerv Surg 2015;7: 666-70 CrossRef Medline

19. Lapergue B, Blanc R, Guedin P, et al. A direct aspiration, first pass technique (ADAPT) versus stent retrievers for acute stroke therapy: an observational comparative study. AJNR Am J Neuroradiol 2016; 37:1860-65 CrossRef Medline

20. Kim YW, Son S, Kang DH, et al. Endovascular thrombectomy for M2 occlusions: comparison between forced arterial suction thrombectomy and stent retriever thrombectomy. J Neurointerv Surg 2017;9:626-30 CrossRef Medline

21. Mokin M, Primiani CT, Ren Z, et al. Endovascular treatment of middle cerebral artery $M 2$ occlusion strokes: clinical and procedural predictors of outcomes. Neurosurgery 2017;81:795-802 CrossRef Medline

22. Gerber JC, Daubner D, Kaiser D, et al. Efficacy and safety of direct aspiration first pass technique versus stent-retriever thrombectomy in acute basilar artery occlusion-a retrospective single center experience. Neuroradiology 2017;59:297-304 CrossRef Medline

23. Hesse AC, Behme D, Kemmling A, et al. Comparing different thrombectomy techniques in five large-volume centers: a 'real world' observational study. J Neurointerv Surg 2018;10:525-29 CrossRef Medline

24. Jadhav AP, Aghaebrahim A, Horev A, et al. Stent retriever-mediated manual aspiration thrombectomy for acute ischemic stroke. Interv Neurol 2017;6:16-24 CrossRef Medline

25. Maegerlein C, Prothmann S, Lucia KE, et al. Intraprocedural thrombus fragmentation during interventional stroke treatment: a comparison of direct thrombus aspiration and stent retriever thrombectomy. Cardiovasc Intervent Radiol 2017;40:987-93 CrossRef Medline

26. Gory B, Mazighi M, Blanc R, et al; Endovascular Treatment in Ischemic Stroke (ETIS) Research Investigators. Mechanical thrombectomy in basilar artery occlusion: influence of reperfusion on clini- 
cal outcome and impact of the first-line strategy (ADAPT vs stent retriever). J Neurosurg 2018 Jan 12:1-10. [Epub ahead of print] CrossRef Medline

27. Mocco JSA, Turk A III. A Comparison of Direct Aspiration vs. Stent Retriever as a First Approach (“COMPASS"): a randomized trial. In: Proceedings of the International Stroke Conference, Los Angeles, CA, January 25, 2018

28. Nogueira RG, Frei D, Kirmani JF, et al; Penumbra Separator 3D Investigators. Safety and efficacy of a 3-dimensional stent retriever with aspiration-based thrombectomy vs aspiration-based thrombectomy alone in acute ischemic stroke intervention: a randomized clinical trial. JAMA Neurol 2018;75:304-11 CrossRef Medline

29. Son S, Choi DS, Oh MK, et al. Comparison of Solitaire thrombectomy and Penumbra suction thrombectomy in patients with acute ischemic stroke caused by basilar artery occlusion. J Neurointerv Surg 2016;8:13-18 CrossRef Medline

30. Nishi H, Ishii A, Nakahara I, et al. Different learning curves between stent retrieval and a direct aspiration first-pass technique for acute ischemic stroke. J Neurosurg 2018 Jan 5:1-8. [Epub ahead of print] CrossRef Medline

31. Stapleton CJ, Leslie-Mazwi TM, Torok CM, et al. A direct aspiration first-pass technique vs stentriever thrombectomy in emergent large vessel intracranial occlusions. J Neurosurg 2018;128:567-74 CrossRef Medline

32. Powers WJ, Derdeyn CP, Biller J, et al; American Heart Association Stroke Council. 2015 American Heart Association/American Stroke Association Focused Update of the 2013 Guidelines for the Early Management of Patients with Acute Ischemic Stroke Regarding Endovascular Treatment: A Guideline for Healthcare Professionals from the American Heart Association/American Stroke Association. Stroke 2015;46:3020-35 CrossRef Medline

33. Fargen KM, Arthur AS, Spiotta AM, et al. A survey of neurointerventionalists on thrombectomy practices for emergent large vessel occlusions. J Neurointerv Surg 2017;9:142-46 CrossRef Medline

34. Tsang AC, Yeung RW, Tse MM, et al. Emergency thrombectomy for acute ischaemic stroke: current evidence, international guidelines and local clinical practice. Hong Kong Med J 2018;24:85-92 CrossRef Medline

35. Romano DG, Cioni S, Vinci SL, et al. Thromboaspiration technique as first approach for endovascular treatment of acute ischemic stroke: initial experience at nine Italian stroke centers. J Neurointerv Surg 2017;9:6-10 CrossRef Medline

36. Mocco J, Zaidat OO, von Kummer R, et al; THERAPY Trial Investigators. Aspiration thrombectomy after intravenous alteplase versus intravenous alteplase alone. Stroke 2016;47:2331-38 CrossRef Medline

37. Gory B, Armoiry X, Sivan-Hoffmann R, et al. A direct aspiration first pass technique for acute stroke therapy: a systematic review and meta-analysis. Eur J Neurol 2018;25:284-92 CrossRef Medline

38. Zaidat OO, Castonguay AC, Linfante I, et al. First pass effect: a new measure for stroke thrombectomy devices. Stroke 2018;49:660-66 CrossRef Medline

39. Mokin M, Fargen KM, Primiani CT, et al. Vessel perforation during stent retriever thrombectomy for acute ischemic stroke: technical details and clinical outcomes. J Neurointerv Surg 2017;9:922-28 CrossRef Medline

40. Lee JS, Hong JM, Kim JS. Diagnostic and therapeutic strategies for acute intracranial atherosclerosis-related occlusions. J Stroke 2017; 19:143-51 CrossRef Medline

41. Maus V, Behme D, Kabbasch C, et al. Maximizing first-pass complete reperfusion with SAVE. Clin Neuroradiol 2018;28:327-38 CrossRef Medline

42. McTaggart RA, Tung EL, Yaghi S, et al. Continuous aspiration prior to intracranial vascular embolectomy (CAPTIVE): a technique which improves outcomes. J Neurointerv Surg 2017;9: 1154-59 CrossRef Medline

43. Tung EL, McTaggart RA, Baird GL, et al. Rethinking Thrombolysis in Cerebral Infarction 2b: which Thrombolysis in Cerebral Infarction scales best define near complete recanalization in the modern thrombectomy era? Stroke 2017;48:2488-93 CrossRef Medline 